A. SADHUKhAN, D. SAHU, B. GANGUly, * N. H. KHAN, * R. I. KUREShY, S. H. R. ABDi, E. SURESH, H. C. BAJAJ (CENTRAL SALT \& MARINE CHEMICALS RESEARCH INSTITUTE, BHAVNAGAR, INDIA)

Oxazoline-Based Organocatalyst for Enantioselective Strecker Reactions: A Protocol for the Synthesis of Levamisole Chem. Eur. J. 2013, 19, 14224-14232.

\title{
Synthesis of Levamisole
}
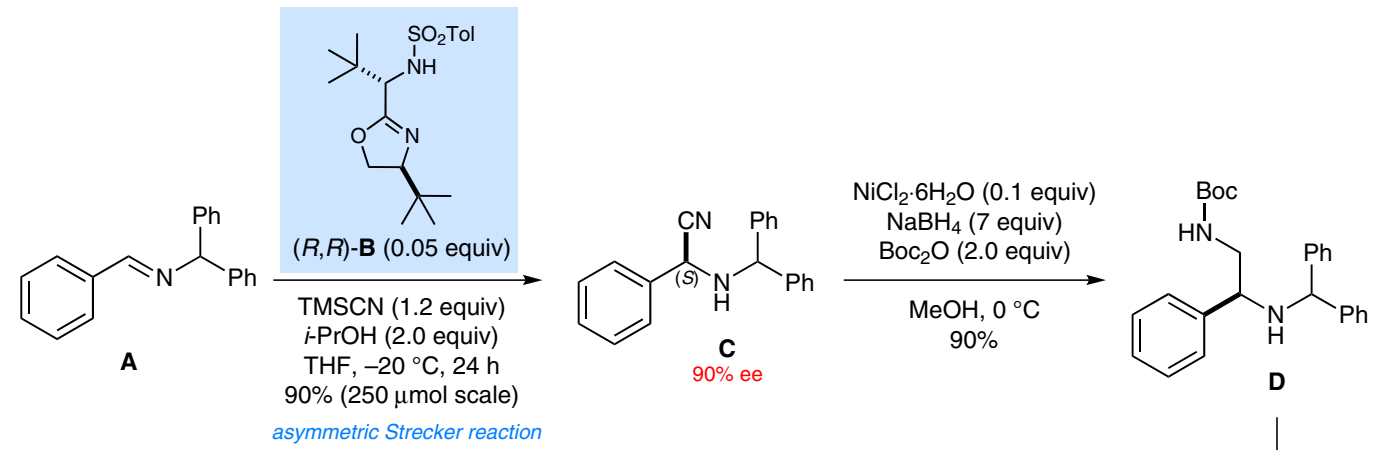

concd $\mathrm{HCl}, \Delta \mid 82 \%$

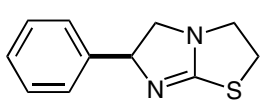

Levamisole

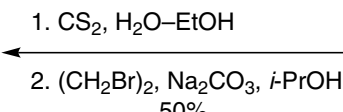
$50 \%$<smiles>NCC(N)c1ccccc1</smiles><smiles>CCCC</smiles>

Category

Synthesis of Natural

Products and

Potential Drugs

\section{Key words}

levamisole

asymmetric Strecker reaction

$\alpha$-aminonitriles

organocatalysis

1,2-diamines

Scope of the substrates in the asymmetric Strecker reaction catalyzed by $(S, S)-B$ :

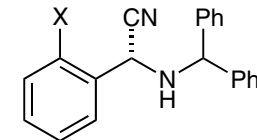

X Yield (\%) ee (\%)

$\mathrm{Me} \quad 90 \quad 94$

$\mathrm{OMe} \quad 93 \quad 96$

$\begin{array}{lll}\mathrm{F} & 78 & 91\end{array}$

Cl $\quad 90 \quad 82$

$\mathrm{NO}_{2} \quad 9^{2}$

\begin{tabular}{lrr} 
& \\
& & \\
\hline $\mathrm{R}$ & Yield (\%) & ee (\%) \\
\hline $\mathrm{Bn}$ & 90 & 91 \\
$\mathrm{CH}_{2} \mathrm{Bn}$ & 90 & 87 \\
$t-\mathrm{Bu}$ & 91 & 93 \\
$i-\mathrm{Bu}$ & 94 & 90 \\
$\mathrm{Hex}$ & 90 & 71 \\
$\mathrm{CH}=\mathrm{CHPh}$ & 93 & 90
\end{tabular}

90

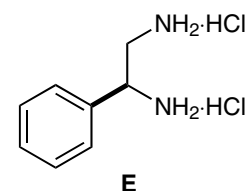

Significance: Levamisole $\left(\right.$ Ergamisol $\left.^{\circledR}\right)$ is an antihelminthic that is currently used to treat worm infestations in livestock. The synthesis of levamisole depicted features an asymmetric Strecker reaction of $\mathrm{N}$-benzhydryl aldimine $\mathbf{A}$ with trimethylsilyl cyanide catalyzed by oxazoline $(R, R)$-B (5 mol\%) as the key step. The chiral $\alpha$-aminonitrile intermediate $\mathbf{C}$ was generated in 90\% yield and $90 \%$ ee.

SYNFACTS Contributors: Philip Kocienski

Synfacts 2014, 10(1), 0007 Published online: 13.12.2013

Dol: 10.1055/s-0033-1340326; Reg-No.: K07213SF
Comment: A study of the scope of the asymmetric Strecker reaction (18 examples) revealed that both alkyl and aryl N-benzhydryl aldimines participate in the reaction to give the corresponding $\alpha$-aminonitriles in good yield and generally $>80 \%$ ee with some exceptions being shown in the box above. For a previous synthesis of levamisole based on asymmetric diamination of styrenes, see: C. Röben et al. Angew. Chem. Int. Ed. 2011 $50,9478$. 